\title{
Professionals at the interface of science: is there more than meets the eye?
}

José M. R. C. A. Santos , Carolina Varela \& Simon Kerridge

To cite this article: José M. R. C. A. Santos , Carolina Varela \& Simon Kerridge (2021):

Professionals at the interface of science: is there more than meets the eye?, Perspectives: Policy and Practice in Higher Education

To link to this article: https://doi.org/10.1080/13603108.2021.1881842

曲 Published online: 09 Feb 2021.

Submit your article to this journal \lceil

Q View related articles $₫$

View Crossmark data $[\pi$ 


\title{
Professionals at the interface of science: is there more than meets the eye?
}

\author{
José M. R. C. A. Santos (D) ${ }^{a}$, Carolina Varela (D) ${ }^{b, c}$ and Simon Kerridge (D) ${ }^{d}$ \\ ${ }^{a}$ Centro de Investigação de Montanha (CIMO), Instituto Politécnico de Bragança, Bragança, Portugal; ${ }^{b}$ Department of Political Science and \\ International Studies, University of Birmingham, Birmingham, UK; ${ }^{C}$ School of Social Sciences and Humanities, Universidade Nova de

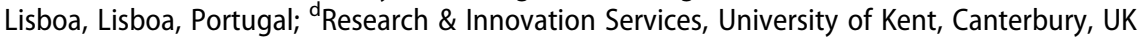

\begin{abstract}
The increasing professionalisation, mixed profiles, and institutional formal recognition of research managers and administrators (RMAs), namely at higher education institutions, has led to an increasing but modest volume of academic studies focused on their professional identity, roles, functions and impact. Based on an extensive literature review, the authors suggest however that current definitions for RMAs miss, or at least do not explicitly address, a crucial part of the research and innovation systems worldwide: the research managers, administrators, communicators, and technicians that work at research funding and policy agencies. It is the authors' opinion that RMAs working at research funding and policy agencies should be addressed as an intrinsic part of the global community as they provide a unique perspective of the overall research and innovation system. They are in fact a missing link in the RMA ecosystem that needs to be addressed for a holistic evolution of contemporary and future research and innovation systems.
\end{abstract}

\section{KEYWORDS}

Professionals at the interface of science (PloS); research management and administration (RMA); research funding agencies; professional identity

\section{Introduction}

In spite of their key role in the performance of research and innovation ecosystems, research management and administration professionals (RMAs) still lack formal recognition by management bodies at institutional level and by other colleagues more widely in their institutions. In fact, they can be regarded as 'invisible intermediaries', as evidenced by Derrick and Nickson (2014). Furthermore, Shelley (2010), refers to the 'interface work between academic and administration' in universities as sometimes problematic. One example given by Shelley is the clash between the freedom and self-governance of academics and the increasingly restrictive audit and accountability rules - trends of the New Public Management. Nevertheless, their professional individuality, roles, and impact have been the subject of a small but increasing number of academic studies (Shelley 2010; Whitchurch 2008; Kerridge and Scott 2018; Enikó, Zsár, and Balázs 2019). Acknowledging, the diversity of roles of these professionals, Agostinho et al. (2020), in an article published in Perspectives, broadened the concept of RMAs to all the professionals working at the Interface of Science (PIoSs), considered as those who 'work in all types of research-performing institutions (RPOs), from universities to research centres (both public and private) and Research \& Development (R\&D) performing companies', meaning the work space linking scientific research to the society at large, including science funding organisations. The authors define 'interface of science' as including 'all areas and activities that are specific to supporting the Research and Innovation ecosystem in addition to research activities themselves'.

However, it can be observed that the research managers, administrators, communicators, and technicians that work at science funding and policy agencies have not specifically been the subject of study, in particular in the context of the PloS professional identity formalisation. Existing references in literature can be found in authors such as Braun (1998), Wenneberg (2001), Schützenmeister (2010), Goldstein and Kearney (2020), and Arnott et al. (2020), who refer to the functions of research management and administration at R\&D funding entities. However, these studies exclude these professionals from the broader setting provided by the PloS definition. This is also evident when analysing the membership profile of existing formal and informal associations of RMAs/PloSs. In fact, the activities carried out by these associations typically restrict themselves, perhaps implicitly rather than explicitly, to PloSs working at public and private higher education institutions (HEls) and research institutions. Seldom do they include PloSs such as practitioners working at science funding and policy agencies. The authors consider this absence as a weakness of these associative communities of professionals as one of their common mission statements is to contribute to the evolution of the national and international research and innovation systems by proposing 
measures and policies that optimise strategic and operational aspects of public and private research efforts. In order to achieve such a goal, it is the authors' opinion that PloSs working at science funding and policy agencies should be acknowledged and consider themselves as an intrinsic part of the PloS community, essential to fulfil the mission of these professionals in the context of research and innovation systems.

This study forms part of a wider research project to systematically analyse the context and impact of these professionals in research and innovation ecosystems and their self-recognition within the PloS community. The overall aim is to contribute to the research studies concerning Research Management and Administration (RMA) by providing an analysis of this missing part of the community, namely their identity, professional paths, and community representation. The following research questions are enquired, the first being addressed in this paper:

(1) Are PloSs working at funding/policy agencies identified and addressed by previous studies as members of this community of RMA professionals?

(2) What are the similarities and differences in terms of profile, functions, and roles between PloSs working at science funding and policy organisations and those working at HEls, research centres and other research performing organisations?

To address the first question, the authors have conducted a systematic literature review in the topic of research funding and science policy making organisations. This was followed by (i) a detailed analysis of the existing literature on PloS, namely those professionals working at science funding and policy making organisations, and (ii) a literature review of previous studies, namely surveys on PloS. The paper ends with a discussion of major conclusions and ideas for future research. Note that throughout this paper the authors use the term 'science' to be interchangeable with 'research' more generally. Indeed, where often people talk about research they often think of the science subjects, it is perhaps analogous with RMA and PloS where the focus can often be on those working in research performing organisations (RPOs) rather than PloS in funding agencies and policy organisations.

\section{Research funding and science policy making organisations}

Funding and policy making agencies are here defined as public organisations financed either directly or indirectly by the state in order to define and/or execute science policies. Furthermore, funding agencies also carry out a science policy influencing function (Braun 1998; Smits and Denis 2014). They are, therefore, at least to some extent, directed by political agendas. Their mission is to facilitate knowledge creation that should be directed to the solution for practical problems in the economic, environmental, social or political sector (Lindgreen et al. 2019). Research Councils, often accumulating funding and policy making roles, are thus an intermediary agency at 'arms-length' from government, or a 'boundary organisation', sitting between the government and the academy. In the UK this is exemplified by the Haldane principle (Bird and Ladyman 2013).

Science policy can be understood as 'the collective measures taken by a government in order, on the one hand, to encourage the development of scientific and technical research and, on the other, to exploit the results of this research for general political objectives' (Caswill 2001). It covers the public sector measures designed for the creation, funding, support, and mobilisation of scientific and technological resources, in the context of the 'knowledge economy'. Also, many countries have by now created science and technology 'observatories', which may be science indicator units, statistical offices or research units on policy.

Policy making organisations were created initially to support public research institutions. In most cases, this has been traditionally ensured through the creation of ministries or central governmental executive decisionmaking bodies specialising in science and technology. With the growing diversification of research funding and performing institutions, many new bodies have appeared that participate in the definition of science and technology policies and recent areas such as science diplomacy. These include now supranational agencies such as the European Research Council (ERC), that tend nowadays to influence national policies more directly, as is the case of the ERC in frontier research.

Another type of entity is one which combines the funding of research and the performing of research. They typically have a public budget with their own scientists (e.g. the Spanish National Research Council - CSIC) but they also fund others. Public agencies are financed from budgets distributed by governments, according to programmes and high-level research orientations. However, international programmes stemming from supranational bodies, such as the European Commission and UNESCO are playing an increasingly important role as research funding organisations, defining and informing research agendas that are implemented by national governments. Such agencies tend to distribute funds on the basis of competitive merit, which allow them to pinpoint the interest of the scientific community in particular topics, namely university and other laboratories in the public and private sectors. These organisations also play an important role in the design and promotion of science and 
technology policies because of their capacity to translate the political orientations into effective actions.

Some agencies are focused on basic research, and cover a wide spectrum of areas of intervention (e.g. the Portuguese Foundation for Science and Technology, and the European Research Council). However, increasingly, funds have been allocated on the basis of performance (e.g. Research England), and funding agencies have adopted mission-oriented, contractbased strategic allocation (Auranen and Nieminen 2010) or hybrid basic-research/mission-oriented profiles (e.g. the National Institute for Health Research in the UK, and the recently created Agency for Clinical Research and Biomedical Innovation in Portugal).

Often, organisations exist that separate academicoriented from innovation-oriented projects. This is the case e.g. in Portugal and the UK (innovation oriented: Portuguese Innovation Agency, Innovate UK; academic oriented: Portuguese Foundation for Science and Technology, Research Councils). Nevertheless, it must be stressed that managing innovation does not just mean managing R\&D (Arvanitis 2009). It also includes other activities that are complementary to it, such as technology and knowledge exchange, and scientific entrepreneurship.

\section{Professionals working at the interface of science (PloS)}

Research Management and Administration (RMA) is a recent field of professionalisation that is mainly focused in the leadership, management and operation of the research enterprise. Its emergence is directly linked to the evidence that the effectiveness of research management activities is key to the success of the research endeavour (Schützenmeister 2010; Huang and Hung 2018). Schützenmeister (2010) refers that 'research management can be described as boundary work that produces couplings between science and the wider society'. The boundary-crossing nature of this professional activity has also been highlighted by other authors such as Whitchurch (2008) and Collinson (2006). In fact, it can be traced back much further when Wenneberg (2001) expressed his view that 'the function of research management is to mediate the two opposing logics of the external societal view on the one side and the internal scientific view on the other', and when Kaplan (1959) characterised RMAs as 'frequently caught in the middle of organizational conflict'.

However, the definition of RMAs is still the subject of discussion among the research community. As Dietz and Ritchey (1996) note: 'identities are derived from occupied social positions and the meanings and role expectations associated with them'. The increasing professionalisation and mixed profiles of RMAs make it difficult to establish their job description and professional identity. For example, some of these professionals have high level qualifications, such as doctorates, and develop 'semi academic functions' (Schützenmeister 2010) and perhaps are identified as 'third space' professionals (Whitchurch 2008), but the majority are purely professional staff, albeit with a high level of academic attainment (Kerridge and Scott 2018).

Existing studies in literature developed to analyse the roles and identities of these professionals include e.g. Kerridge and Scott (2018), Poli (2018), Schützenmeister (2010), Longden (2008) and Collinson (2006), addressed below.

Collinson (2006) developed a project to investigate the occupational life-worlds of research administrators in the UK. A striking finding was the wide range of roles and divergent responsibilities covered by the title of 'research administrator', along with the boundarycrossing, ambiguous nature of much of the research administration work. Moreover, the results stress the identity issues of these professionals, related to their perception as 'mere non-academics'.

Schützenmeister (2010) conducted a study to analyse the skills that researchers and RMAs may have in common, including the career pathways, diversification entry and skills of both career types. In terms of skills, the author aimed to understand those coming from academia from those coming from high education management. It was noted that scientifically trained people are often hired as specialists in research management, constituting a new professional role. In contrast to pure administration, the new research managers make decisions with reference to scientific knowledge and the societal ecosystem of research.

Poli (2018) has provided an extensive review of the roles, professional development, and evolution of the research management profession. Nevertheless, the analysis does not include professionals working at funding and policy making agencies.

\section{PloS at public and private science funding and policy making organisations}

Professionals working at funding and policy making agencies have been addressed in the existing literature mostly from science policy definition/application points of view. For example, Braun (1998) stresses the role of funding agencies in the cognitive development of science but only addresses the policy level, not the operational one, nor the actual PloSs in charge of defining and implementing science policies. Nevertheless, Braun does mention that it is acknowledged that, in funding agencies, administration roles have been taken by 'scientific educated administrators', due to the specificities of tasks involved in developing funding procedures, and the need for administrators with good contacts in the scientific community and 
which were familiar with the values, norms, and procedures of scientists.

Wenneberg (2001) states that research management 'can be done at different levels by researchers, research managers, university rectors, research agencies, research councils etc.' This clearly supports the science interface nature of research management functions executed at various levels of the 'science value-chain'. Moreover, Wenneberg considers that a central task for research managers is to present changes in the political environment to the researchers and help them navigate in the sometimes seemingly chaotic system. And also that research management has to catch both the potentiality and the necessary demands of research and present it to the political or administrative system. He concludes by stating that 'we need more management to make the scientific system and the science policy system work together'. Thus, Wenneberg laid the foundation for research managers and administrators being identified as working at the interface of science.

Schützenmeister (2010) addresses the different forms of research management, mentioning the research management at the funding level. The author observed that research management is not carried out by a single power or principal at the top of the research system and by its agents within a clearly structured hierarchy. It is instead distributed to a large number of more or less independent actors dispersed over different levels of hierarchy, the political system, and within research organisations. Therefore, although not explicitly, the author does recognise the existence of RMAs 'outside' research organisations. With regard to this, according to the author, 'program managers do not only translate societal problems in research opportunities, but they are also mediators who observe scientific development closely and try to relate new research areas to political agendas'. However, this reference is limited to research management roles and does not include e.g. technology transfer professionals and science communicators.

Mention should be made to the fact that the existence of RMA professionals working at research funding agencies has been referred to by Kerridge in his doctoral thesis (Kerridge 2012).

A recent review by Poli (2018) provides further evidence that today's widely recognised research management job profiles do not include professionals working at funding and policy making organisations. In fact, no mention is made of these professionals in the extensive review by Poli and colleagues.

Moreover, according to Arnott et al. (2020) program managers at public funding agencies are key actors involved in designing, implementing, and tracking the impact of funding models. The authors also mention that particularly relevant to linking science with action, program managers also help fill gaps between the kind of knowledge that societal actors need and the kind of knowledge scientists are capable of producing. And, also, that 'program managers in public agencies work in service not only to the scientific community but also to society that calls upon and funds science to help solve societal challenges'. They are therefore professionals at the interface of science. The authors further state that expanding a funding agency's mission and role to aid in the production of actionable research may require capacity building to support these kinds of intermediary functions. For example, supporting these new roles may necessitate the cultivation of additional skills, capacities, and funding. The potential for a new role for funders also raises questions about appropriate skill sets, job descriptions, and professionalisation of a program management community seeking a more hands-on, interactive, and supportive role to foster the actionability of the research they fund.

\section{Surveys on PloS}

There are no known in-depth studies found in the literature having a specific focus on PloSs working at funding and policy agencies. However, some field studies do provide useful information on PloS in general and evidence that support the existence of the 'hidden' community of professionals is addressed in this study.

Shelley (2010) conducted a survey study to analyse the transformations of roles and career experiences of research managers and administrators in the universities in the United Kingdom. The study showed as main conclusions that RMAs had a diversity of roles and a wide range of responsibilities. Shelley (2010) contextualises academic qualifications as an accumulation of 'cultural capital' in RMAs, and indicates a lack of recognition, diversified roles and increased responsibilities taken by these professionals, which lead to tensions in the academic sector.

Kerridge and Scott (2018) developed the Research Administration as a Profession (RAAAP) project aimed at obtaining a snapshot of the research management and administration profession around the world. The main objectives of the survey were to inquire on the perceptions of the importance of technical skills and transversal skills of these professionals, and to collect demographic information. From the respondents, $0.7 \%$ and $0.6 \%$ could be identified as working in research funding and governmental departments, respectively. Professionals working at charities, private companies, and hospitals represented $0.3 \%$, $0.9 \%$, and $3.3 \%$, respectively. Thus, a total of $5.8 \%$ of the respondents work at non-research performing organisations. This clearly indicates that there is a possible key 'hidden' community of PloSs that needs to 
gain visibility in the RMAs professional context. Note however that, due to the nature of the survey methodology, this group is likely to be under-represented in the response set, because they may be unlikely to be members of the associations that distributed the questionnaire to their members.

In face of the above, while important studies were conducted, more research is needed to broaden the scope and professional frameworks of these professionals. Thus, in a forthcoming study, the results concerning an on-going international survey on PloSs working at science funding and policy making entities will be presented.

\section{Conclusions}

In a nutshell, this paper proposes an expansion of the traditional conceptualisation that PloSs are centred almost exclusively around RPOs. It builds the foundation for further discussion on the professional profiles, roles, and impacts of PloSs working at research funding and policy making organisations (and other non-research performing actors in contemporary research and innovation ecosystems).

Because of the expertise and the diverse tasks of PloSs, these professionals are required to share their advanced knowledge and skills with their peers and varied stakeholders across research and innovation ecosystems. As suggested in this study, they are key to bridge research production, societal needs and the political system.

Thus, it is the authors opinion that these professionals should be formally recognised as specialised staff belonging to a wider community sharing a common mission: the support of the advancement of research to the benefit of society. This would contribute to (1) their professionalisation, including development of relevant skills and competences, through extended access to training and professional development activities, typically provided by professional associations of RMAs, (2) an increased sense of community and, therefore, facilitated communication with PloSs working at e.g. research performing organisations, that, among other advantages, would lead to increased interchange of best practices, specific needs and opportunities among these professionals. Consequently, ultimately, the whole research and innovation ecosystem would gain in effectiveness and efficiency.

These aspects are currently being addressed in a research project led by the authors that is expected to provide empirical evidence testing the above discussed theoretical considerations and constructs.

\section{Acknowledgements}

José M. R. C. A. Santos is grateful to the Foundation for Science and Technology (FCT, Portugal) and FEDER under
Programme PT2020 for financial support to CIMO (UIDB/ 00690/2020). José Santos: Conceptualization, Methodology, Project administration, Resources, Writing - original draft preparation, Writing - review \& editing. Carolina Varela: Conceptualization, Methodology, Project administration, Resources, Supervision, Visualization, Writing - review \& editing. Simon Kerridge: Methodology, Project administration, Writing - review \& editing.

\section{Disclosure statement}

No potential conflict of interest was reported by the author(s).

\section{Funding}

José M. R. C. A. Santos is grateful to the Foundation for Science and Technology (FCT, Portugal) and FEDER under Programme PT2020 for financial support to CIMO [grant number UIDB/00690/2020].

\section{Notes on contributors}

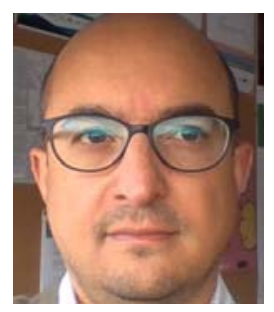

José M. R. C. A. Santos, Science and Technology Manager and Assistant Researcher at the Polytechnic Institute of Bragança (Portugal). PhD (ULeeds UK), Chem. Eng. (UCoimbra - Portugal), post-graduations in Professional Project Management and in Environmental Technology. Project Management Professional (PMP). External expert (project proposals evaluation) for the European Commission (FP7, H2020), among other national and international R\&D funding bodies. Participated in 20 international and national research and innovation projects (coordinator of 6). His research interests comprise $R \& D$, innovation and project management at higher education institutions and, more recently, professionals working at the interface of science.

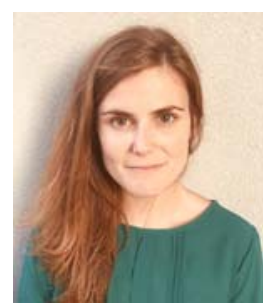

Carolina Varela is a $\mathrm{PhD}$ candidate of Political Science and International Studies at the University of Birmingham, United Kingdom. She currently is a preaward advisor at NOVA School of Social Sciences and Humanities of Universidade Nova de Lisboa, Portugal. She has been a research manager for six years, including one year at the Asian Institute of Management in Metro Manila, the Philippines. Previous experience includes being a manager of international cooperation projects in Spain. She is an active member of several Portuguese research managers and science communicators' networks. Her research interests focus on the comparative analysis and international benchmarking of RDI policies.

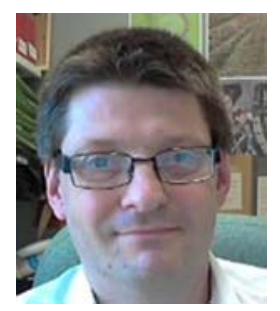

Simon Kerridge, Director of Research Policy \& Support, University of Kent, UK. Simon has been a research manager and administrator for over 25 years, the past eight leading the research office at Kent. Simon is an EARMA Board member, and also sits on the Annual Conference Programme, and Awards Committees. He sits on the NCURA Select Committee for Global Affairs, is a past chair of ARMA, the UK association, and acts as an expert for the EU funded 
foRMAtion project. Simon leads the INORMS (International Network of Research Management Societies) RAAAP (Research Administration as a Profession) Task Force that is collecting longitudinal data about the profession internationally. This follows the initial, NCURA funded, RAAAP project from 2016. Simon has also recently been awarded a follow-on RAAAP Analysis project.

\section{ORCID}

José M. R. C. A. Santos (D) http://orcid.org/0000-0003-21034085

Carolina Varela (D) http://orcid.org/0000-0002-4804-2950

Simon Kerridge (1) http://orcid.org/0000-0003-4094-3719

\section{References}

Agostinho, Marta, Catarina Moniz Alves, Sandra Aresta, Filipa Borrego, Júlio Borlido-Santos, João Cortez, Tatiana Lima Costa, et al. 2020. "The Interface of Science: The Case for a Broader Definition of Research Management." Perspectives: Policy and Practice in Higher Education 24 (1): 19-27. doi:10.1080/13603108.2018.1543215.

Arnott, James C., Christine J. Kirchhoff, Ryan M. Meyer, Alison M. Meadow, and Angela T. Bednarek. 2020. "Sponsoring Actionable Science: What Public Science Funders Can Do to Advance Sustainability and the Social Contract for Science." Current Opinion in Environmental Sustainability 42: 38-44. doi:10.1016/j.cosust.2020.01.006.

Arvanitis, Rigas. 2009. "Science and Technology Policy." In Encyclopedia of Life Support Systems (EOLSS), Developed under the Auspices of the UNESCO. Paris, France: Eolss Publishers. https://www.eolss.net.

Auranen, Otto, and Mika Nieminen. 2010. "University Research Funding and Publication Performance-An International Comparison." Research Policy 39 (6): 822834. doi:10.1016/j.respol.2010.03.003.

Bird, Alexander, and James Ladyman. 2013. “Free Inquiry: The Haldane Principle and the Significance of Scientific Research." Social Epistemology Review and Reply Collective 2 (7): 14-22. https://wp.me/p1Bfg0-Of.

Braun, Dietmar. 1998. "The Role of Funding Agencies in the Cognitive Development of Science." Research Policy 27 (8): 807-821. doi:10.1016/S0048-7333(98)00092-4.

Caswill, C. 2001. Science Resource Decisions - Principals, Agents and Games. Science Policy - Setting the Agenda for Research. Aarhus, Denmark: The Danish Institute for Studies in Research and Research Policy.

Collinson, Jacquelyn Allen. 2006. "Just 'Non-Academics'?: Research Administrators and Contested Occupational Identity." Work, Employment and Society 20 (2): 267-288. doi:10.1177/0950017006064114.

Derrick, Gemma, and Alicen Nickson. 2014. "Invisible Intermediaries: A Systematic Review into The Role of Research Management in University and Institutional Research Processes." The Journal of Research Administration 45: 11-45.
Dietz, B. E., and P. N. Ritchey. 1996. "The Relative Influence of Individual Identities, Identity Accumulation, and Identity Accumulation, and Identity Combinations on Facets of Psychological Well-Being." Sociological Spectrum 16: 1-25.

Enikó, V., V. Zsár, and Z. Balázs. 2019. Research Management and Administration: A Profession Still to Be Formalized. Budapest, Hungary: HÉTFA Research Institute and Center for Economic and Social Analysis.

Goldstein, Anna P., and Michael Kearney. 2020. "Know When to Fold 'Em: An Empirical Description of Risk Management in Public Research Funding." Research Policy 49 (1), doi:10. 1016/j.respol.2019.103873.

Huang, Jun Song, and Wei Loong Hung. 2018. "Building the Science of Research Management: What Can Research Management Learn from Education Research?" The Journal of Research Administration 49: 11-30.

Kaplan, Norman. 1959. "The Role of the Research Administrator." Administrative Science Quarterly 4 (1): 20. doi:10.2307/2390647.

Kerridge, S. R. 2012. "Electronic Research Administration [DProf]." University of Sunderland.

Kerridge, Simon, and Stephanie F. Scott. 2018. "Research Administration Around the World." Research Management Review 23 (1): 35-44.

Lindgreen, Adam, C. Anthony Di Benedetto, Camilla Verdich, Joëlle Vanhamme, Vinod Venkatraman, Steven Pattinson, Ann Højbjerg Clarke, and Zaheer Khan. 2019. "How to Write Really Good Research Funding Applications." Industrial Marketing Management 77 (February): 232-239. doi:10.1016/j.indmarman.2019.02.015.

Longden, Bernard. 2008. "Changing Identities in Higher Education: Voicing Perspectives." British Journal of Educational Studies 56 (2): 235-236. doi:10.1111/j.14678527.2008.00402_4.x.

Poli, Susi. 2018. "Understanding Diversity, Gender Equality, and Cultures in Research Management and Administration." In Research Management: Europe and Beyond, 289-317. Elsevier. doi:10.1016/B978-0-12805059-0.00014-6.

Schützenmeister, Falk. 2010. University Research Management: An Exploratory Literature Review. Berkeley, USA. https://escholarship.org/uc/item/77p3j2hr.

Shelley, Louise. 2010. "Research Managers Uncovered: Changing Roles and 'Shifting Arenas' in the Academy." Higher Education Quarterly 64 (1): 41-64. doi:10.1111/j. 1468-2273.2009.00429.x.

Smits, Pernelle A., and Jean Louis Denis. 2014. “How Research Funding Agencies Support Science Integration into Policy and Practice: An International Overview." Implementation Science 9 (1), doi:10.1186/1748-5908-9-28.

Wenneberg, S. 2001. Research Management as an Instrument. Science Policy - Setting the Agenda for Research. Aarhus, Denmark: The Danish Institute for Studies in Research and Research Policy.

Whitchurch, Celia. 2008. "Shifting Identities and Blurring Boundaries: The Emergence of Third Space Professionals in UK Higher Education." Higher Education Quarterly 62 (4): 377-396. doi:10.1111/j.1468-2273.2008.00387.x. 